\title{
Entrevista con el maestro Fernando Cruz Kronfly
}

Fabio Martínez ${ }^{1}$

Universidad del Valle

\section{El facebook manifiesta el desespero del yo contemporáneo}

Conocí a Fernando Cruz Kronfly en los claustros de la Universidad Santiago de Cali, que estaba situada en aquella casona del centro de Cali, símbolo emblemático de la cultura caleña.

Cruz Kronfly hacía parte de un grupo de intelectuales que fueron llamados a la academia por Álvaro Pío Valencia y Estanislao Zuleta, quienes dirigían los destinos del alma mater. Era un grupo exquisito por donde pasaron: Enrique Buenaventura, Anthony Sampsom, Alcibíades Paredes, Tomás Quintero, Marco Fidel Chávez, Norman Alhach, Evelio Espínola, Luz Helena Giraldo, Mario Díaz, Gladys Conde, Sebastián Solari, Eduardo Serrano y Javier y Rodrigo Navarro, ente otros.

Eran los años setenta. Una década donde nadie pensaba en la guerra, en la cultura del crimen y el narcotráfico, y en la debacle del país, que durante cuarenta años iba a arrojar seis millones de víctimas.

Ante el miedo que imperó durante estas cuatro décadas, Cruz Kronfly se refugió en la formación de los jóvenes y en el mundo de los libros.

Cuarenta años después, y con la ilusión de un acuerdo de paz, que está por cocinarse en el país, hablé con mi maestro y amigo Fernando Cruz Kronfly, en la Librería Nacional del Oeste.

Esto fue lo que me dijo:

\footnotetext{
${ }^{1}$ Profesor de la Universidad del Valle (Cali). Doctorado en Semiología de la UQAM, Montreal, Canadá. Es autor de libros de crítica literaria como El viajero y la memoria. Un ensayo sobre la literatura de viaje en Colombia (2000) y de varias obras de ficción. Su último libro se titula Los viajes de la música. Música y poesía afroamericana (2015). Escribe semanalmente una columna de opinión en el diario El Tiempo.
} 


\section{El destierro}

Fabio Martínez: Fernando, tu última novela se titula Destierro (Sílaba Editores). En esta obra se habla del doble exilio que vive el personaje llamado el Habibe. Háblanos de tus orígenes. ¿Cómo un escritor colombo-sirio, como tú, vive el destierro?

Fernando Cruz Kronfly: Si debiera caracterizar mis orígenes tendría que reconocer que soy bicultural. La presencia del mundo árabe, por el costado materno, es muy fuerte. Mi padre, colombiano, resultó colonizado por la tradición alimentaria árabe y, en general, mediterránea. Siria es hoy un país de muchos conflictos interiores. Ahora mismo la ciudad de origen de mi familia materna, Homs, está totalmente despedazada, bombardeada. Siria es el país del mundo con más desplazados. Le sigue Colombia. Mira qué macabra coincidencia.

1926 fue el año del éxodo, eufemismo que se utiliza a veces para ocultar el desplazamiento y el desarraigo forzado. Mi abuelo y mis tíos, incluida mi madre, viajan a Colombia en busca de refugio. Colombia era América, tierra de la esperanza. Mamá tenía entonces trece años. Soy entonces originario de una familia desplazada por hechos de violencia en el Medio Oriente, derivados de conflictos religiosos. Hoy vemos cómo retornan estos conflictos alrededor del fundamentalista, degollador y asesino "Estado Islámico". Mi familia era cristiana ortodoxa y, como tal, provenía de una tradición cultural abierta a occidente. Muchos años después, cuando me hice mayor y creía haber empezado a entender algunas cosas, me sorprendía ver cómo mis tías y tíos maternos profesaban ideales liberales y democráticos. Algunos de mis tíos árabes eran masones y se declaraban librepensadores. Eran liberales ideológicos y mundanos.

Durante la guerra mundial de 1914, mi tío Nury iba a ser reclutado como soldado para pelear contra no sé quién, y mi abuelo, para protegerlo, lo ocultó en un último cuarto al final de la casa. Y le contrató un profesor de laúd. El encierro de mi tío duró cuatro años, que fueron muy bien invertidos en las clases de música. Cuando terminó la guerra y pudo salir al sol, mi abuelo lo envió a Cartago, en el Valle del Cauca. Fue enviado como punta de lanza para hacer un camino seguro para todos. Hacer una avanzada económica en la tierra prometida y alquilar 
una casa grande y vivir en paz. Abrió entonces un almacén de telas en Cartago. En aquella época, Cartago era una ciudad próspera, punto final de la navegación por el río Cauca a través del rio La Vieja. Esto hizo de Cartago una ciudad con un gran movimiento comercial exportador alrededor de la economía del café, que irradiaba desde el viejo Caldas. En la ciudad había trilladoras y, claro, alrededor de esta economía fuerte, se fue desarrollando un sector comercial significativo. A su vez, por el río Cauca venían a Cartago, desde Buenaventura, mercancías de importación de todo tipo, con destino al viejo Caldas e incluso Antioquia, por la vía de Manizales, Aguadas y hasta La Pintada, que era la ruta de la arriería.

Un año más tarde llegó toda la familia materna. Mi tío Nury era ya un personaje querido por todos. Tocaba el laúd, cantaba como un canario, tenía enamoradas a las muchachas y era un dulce y educado bohemio. En el almacén que fundó había una trastienda donde él se reunía con otros exiliados árabes y con colombianos, a tomar aguardiente y cantar música colombiana. El primer instrumento musical que escuché en casa fue el laúd. Mi madre y mis tías hablaban árabe entre ellas y desde el vientre materno esa fonética me fue familiar. Con las vecinas se comunicaban en "su castellano". El día que se casaron mis padres, mi abuelo materno les dio de regalo dos palmas de dátiles, que nunca supe de dónde salieron y que fueron sembradas en el inmenso solar de nuestra casa de Guadalajara de Buga. Yo alcancé a ver las palmas de dátiles cargadas de racimos y nos pasábamos comiendo dátiles que terminaban de madurar al sol sobre tendidos de hojas de periódicos. Esto fue antes de nuestra migración a Cali.

Mi padre tulueño era un hombre realmente culto. Librepensador ilustrado. Leía a mamá capítulos de Víctor Hugo, Balzac, Gogol, Gorki, Dostoievski. Se sentaba a leer a la sombra de las palmas de dátiles a comer kibbe y beber coñac francés. La biculturalidad me asediaba por todas partes. De esta experiencia cotidiana nació en mí el espíritu del desterrado, en términos de Todorov. Desde que nací fui un desterrado que no era ni de aquí ni de allá. Eso es lo que cuento en mi última novela, que es el relato de un doble destierro. 
En la novela hay algunas palabras árabes, como "habibe", que es el nombre del héroe. ¿Qué significa "habibe”?

El habibe es el ser querido, el amado.

\section{La educación sentimental}

Háblame de tu juventud; de los años setenta. Los años de la militancia de izquierda y las protestas estudiantiles. Esa interesante década que vivió Cali y el país.

Yo estudié en el colegio Berchmans, que era regentado por jesuitas. A ellos debo mucho en términos de disciplina y formación en la lógica formal aristotélica. Desde aquellos años del bachillerato, empecé a advertir que en el seno de los jesuitas había dos posiciones: una, el jesuitismo tradicional de los curas godos tradicionales y otra, muy distinta, la izquierda jesuítica que todavía se conserva y de la que derivó Francisco de Roux, padre provincial de los jesuitas y considerado un "cura rojo". De Roux hizo un gran trabajo social en el Magdalena Medio y llegó a ser padre provincial de los jesuitas.

Te refieres a esa corriente de jesuitas que se aglutinó alrededor de Cinep, el Centro de Investigación y Educación Popular.

Del Cinep, exactamente. De la corriente ideológica de la que, al parecer viene el Papa actual, discípulo de Ignacio de Loyola.

¿Del papa Francisco?

Sí, él es jesuita, y uno lo nota en su actitud informal, más cercana al ejemplo de Francisco de Asís que a los grandes conciliábulos corrompidos del Vaticano. Lo que quiero decir es que, como derivación de esto, desde aquel tiempo hubo en el colegio Berchmans un cura que influyó sobre algunos de nosotros. Se llamó Francisco Javier Mejía y tenía trabajo social en el barrio de invasión La Isla. Nosotros íbamos allí sábados y domingos como estudiantes de bachillerato. Hacíamos trabajo de acción social. Los pobladores de La Isla eran campesinos expulsados de sus tierras por causa de la violencia de los años 50 . Yo hice mis estudios de bachillerato en los años 60. Los campesinos que llegaron a poblar el barrio La Isla y los extramuros de la ciudad vestían de "poncho", carriel y machete al cinto. Vivían en "cambuches" impro- 
visados de guadua y cartón. Nosotros llegábamos allí y los desplazados nos recibían con café y agua de panela. Esta situación me marcó, definitivamente. Luego, leyendo el 18 Brumario de Karl Marx y, sobre todo, el capítulo sobre la acumulación originaria de capital, en Inglaterra, comprendí mejor la situación social de nuestros campesinos. La preocupación de Marx no es allí «marxista» sino ante todo humanista, pienso. Se trata de una preocupación solidara respecto de la situación de pobreza e injusticia de los campesinos expulsados. Así ocurrió mi aproximación al pensamiento socialista: por la vía de la solidaridad humana con los desposeídos y por la vía del entendimiento de las leyes sociales que producen estos fenómenos. El pensamiento socialista analítico se unió a la solidaridad humana que venía de mi formación jesuítica un tanto asistencialista. El sentimiento de piedad por el otro, que es un sentimiento cristiano, considera al otro como mi semejante. Más tarde, leyendo a Finkielkraut, confirmo que el primer paso en la construcción Occidental, ecuménica y universal según la cual todos los seres humanos tenemos algo en común lo dio el cristianismo. Y lo pudo dar por su concepción monoteísta, puesto que si Dios es uno solo y es el creador de cuanto existe, incluidos los seres humanos de todos los colores, entonces debemos tener algo en común. Esto que todos los seres humanos por igual tenemos en común es, según el mito creacionista como hijos del mismo Dios, nuestra condición de "semejantes".

Este pensamiento terminó por insertarse en la modernidad, se laicizó, se resignificó y terminó convertido, pienso, en el concepto de ciudadanía universal y en el fundamento, ya secular y revolucionario francés, de los Derechos Universales del Hombre y del Ciudadano.

En mi juventud, el camino hacia la izquierda se hizo por la vía de los sentimientos de solidaridad humana hacia los semejantes, que eran los humildes desposeídos de todo. Luego estas representaciones se fueron racionalizando y, a la luz del pensamiento marxista, se fueron convirtiendo en una especie explicación crítica respecto de las causas que causan la miseria como negación del derecho a la vida y del respeto por el otro.

Para ser sincero, lo que más me interesó del pensamiento de Marx, fue su componente explicativo de las leyes sociales. Es decir, el meca- 
nismo de relojería de lo histórico y de lo social. Dicho de otra manera, el materialismo. Ingresé al pensamiento de Marx, no exactamente por la vía del resentimiento social sino por la vía de la solidaridad con los humildes. No tenía motivo alguno para ser un resentido. Mi interés era intelectual. Ahora pienso que el marxismo tiene claramente tres componentes: el utópico social, el mesiánico y el analítico.

Mi interés de aquel entonces por el pensamiento de Marx se debió al componente analítico. El componente mesiánico parte del supuesto de que la clase obrera es una especie de sustituto de Cristo que va a salvar a la humanidad; según esto, para los marxistas mesiánicos la clase obrera es el mesías de la humanidad. Incluso, la clase obrera va a salvar a los mismos capitalistas que se encuentran prisioneros del capital y son sus víctimas. Marx idealizó a la clase obrera y la convirtió en el mesías de la humanidad.

El componente utópico tiene que ver con "un no lugar". Un lugar añorado e idealizado, especie de paraíso aún no dado en esta tierra y al que hay que ir. Un "Utopos", que consiste en imaginar un lugar futuro que no aún no existe y que hay que construir. Un mundo perfecto, ideal, pero que no existe. Este "utopos", especie de cielo en la tierra, proviene de la tradición milenarista judeocristiana, de la cual Marx era heredero.

El componente analítico al que me afilié desde un comienzo está en aquellos textos en los cuales Marx expuso las relaciones causales estructurales de lo social y de la historia de las sociedades humanas. Cómo funciona la estructura social en general y la capitalista en particular. Las exposiciones que hace Marx sobre la guerra civil en Francia y El 18 Brumario de Luis Bonaparte, son piezas maestras de cualquier análisis histórico y análisis social sobre aquella época, metodología que hoy veo incorporada de manera silenciosa en parte fundamental de la sociología contemporánea.

No es necesario que un sociólogo contemporáneo se confiese hoy como seguidor de Marx en cuanto al método. El pensamiento de Marx se incorporó de manera natural y silenciosa como ganancia teórica de la humanidad en el campo de la ciencia social. Forma parte del método ya asimilado por los pensadores sociales. Superado, por supuesto, el determinismo económico y ese tipo de cosas que no están en Marx, 
ciertamente, sino en algunos de sus seguidores En contra de este determinismo economicista, pienso, Louis Althusser y otros intelectuales de los años setenta se propusieron una lectura distinta de Marx; sobre todo con la incorporación del método estructuralista a propósito del análisis social, tal como ocurrió en el campo de la lingüística y la antropología de Lévi-Strauss.

Este fue en términos generales mi punto de partida. Entre 1961 y 1967 hice mis estudios universitarios en Derecho y Ciencias Políticas en la universidad La Gran Colombia, en Bogotá. En aquella época yo era un "lector enfermo". Esto era lo único que hacía: leer al desayuno, leer y leer hasta el amanecer. Yo estudiaba mi carrera sólo para los exámenes finales y, como leía tanto, tenía buenos presupuestos lógicos y filosóficos. Luego, cuando me recibí, volví a Cartago, y ejercí como juez por algunos años.

Aparte de Marx, ¿qué otras lecturas te marcaron?

En aquella década estaba en boga el existencialismo. Yo leí a Sartre, pero con mayor entusiasmo a Albert Camus. Es que Camus es inmenso. Era una especie de autodidacta que leía de todo. Por mis manos pasaron Kant, Darwin y sus teorías evolucionistas, Jasper y Heidegger. Leía las teorías genéticas, el ADN y la composición bioquímica de los seres humanos. Mi formación como lector era fundamentalmente ensayística. De allí viene mi predilección por el ensayo como género. Pero, así mismo, amaba la ficción literaria. La necesitaba visceralmente. En la universidad escribí poesía y obtuve muy joven el primer lugar en un concurso nacional universitario de cuento patrocinado por la Universidad Externado de Colombia, de Bogotá.

¿Fue tu primer cuento? ¿Cómo se llamaba?

"El sordomudo de Paoleta". Por aquellos días del premio, yo estaba leyendo el libro de cuentos El llano en llamas, de Juan Rulfo. Esa lectura me cambió el mundo ficcional y lingüístico que hasta entonces había conocido en la literatura rusa y europea, dominante en la biblioteca personal de papá.

¿Rulfo es posterior a los autores que te recomendaba tu padre? Mi padre nunca me recomendó leer nada. Yo sólo lo veía comprar li- 
bros, leer constantemente y hasta dormirse con los libros abiertos en el pecho. Lo que recibí de él fue el formidable ejemplo del amor y la pasión por los libros, la cultura letrada y el libre pensamiento. Murió en 1957 cuando yo sólo tenía 14 años y leía al Pato Lucas. En esa época ya existía, claro, la literatura latinoamericana: Miguel Ángel Asturias, José María Arguedas, Roberto Arlt, para citar unos pocos. Pero esta no era una literatura reconocida, al menos por papá. En cierto modo, la literatura latinoamericana estaba "ninguneada". La literatura francesa, inglesa, rusa y norteamericana eran el canon de lo que había que leer.

Cuando cae en mis manos El llano en llamas y, particularmente el cuento "Macario", mi vida como lector se transforma. Aún no había caído a mis manos Pedro Páramo. Mis lecturas de entonces, que influenciadas más por la biblioteca de mi padre que por él mismo, aunque su biblioteca era él mismo, eran Víctor Hugo, Stendhal, Balzac, Gorki, Gogol y Dostoievski. Cuando muere mi padre, yo me hundo de cabeza en su biblioteca. Este episodio es conmovedor, pues hundirme en la biblioteca fue una manera de no dejar morir a papá. De hablar con él en silencio a través de lo que escribía y resaltaba en los libros mismos. Recuerdo que tenía catorce años y estaba fuertemente identificado con él y con su misterioso mundo de los libros, que sólo veía de lejos.

Desde muy joven tuviste amigos que más tarde fueron grandes intelectuales.

En el colegio Berchmans conocí a Álvaro Escobar Navia y nos hicimos muy amigos. Ambos vivíamos en el barrio Juanambú, muy cerca de la sinagoga judía. Álvaro fue un joven enfermizo; sufría de nefritis y tenía por lo tanto problemas con el corazón y los riñones. Por esto murió a los treinta y ocho años de edad, cuando era rector de la Universidad del Valle.

En el colegio Álvaro fue indisciplinado. Como era en extremo inteligente poco estudiaba. Cierta vez que iba a perder el año, ya para los exámenes finales nos invitó a un grupo de tres compañeros suyos para que fuéramos a estudiar con él a la finca de sus padres que quedaba en La Cumbre, sobre la carrilera por donde pasaba el tren. En vez de dedicarnos a estudiar en serio, Álvaro se puso a tocar el piano, y nosotros nos dedicamos a leer poesía y a beber aguardiente a la orilla de la carri- 
lera, para ver el tren pasar con las luces encendidas. Fue en esa tertulia irresponsable, que le confesé a mi amigo Álvaro, ya en tragos, que yo estaba leyendo a un tal Dostoievski; y él me dijo que estaba leyendo a un tal Balzac. A partir de ese momento, surgió entre nosotros un diálogo precioso hasta que terminamos el bachillerato y después prosiguió cuando nos hicimos adultos.

Con Estanislao Zuleta hablé unas dos a o tres veces, pero sabía de él y, sobre todo, de su obra. Lo que quiero decirte es que yo nunca hice parte del grupo de aduladores que se sentaban en su mesa para "canalearlo". Fue Escobar Navia, Álvaro Pío Valencia como rector de la Universidad Santiago de Cali, y yo, quienes lo convencimos de que aceptara venir a Cali como vicerrector de la Universidad.

Álvaro Pío Valencia, ¿el hijo del poeta Guillermo Valencia?

Sí, el mismo. Álvaro Pío vino de Popayán a Cali y con Zuleta fueron, respectivamente, rector y vicerrector de la Santiago de Cali. Estas fueron mis primeras amistadas intelectuales. Luego vinieron Jorge Ucrós, que acababa de llegar de Europa, y la famosa mesa del café Los Turcos donde cada viernes en la tarde coincidíamos con Ramiro Madrid, Jaime Galarza, Yamil Puentes, Anthony Sampson (quien venía de Canadá), y otros. Recuerdo que Zuleta, con voz grave nos decía: "Hay que leer a Lévi-Strauss". Al día siguiente, íbamos a la Librería Nacional o la Librería Letras de Aurita Bustamante, y comprábamos Lo crudo y lo cocido o Las estructuras elementales del parentesco.

La Universidad Santiago de Cali, situada en la casona de la esquina de la carrera quinta con calle séptima, era un hervidero de ideas donde leíamos junto con los estudiantes, en grupos informales constituidos, temas relacionados con Sicoanálisis, Lingüística, Antropología, Marxismo y Literatura. Esta era la dieta.

\section{Marx y la generación perdida}

¿Cuándo aparece tu primer libro de cuentos, Las alabanzas y los acechos?

Las alabanzas y los acechos aparece en el año de 1972. Son cuentos más maduros. Con este libro obtuve el premio en el Concurso Nacional 
de Cuento convocado por la revista Vivencias de Cali. En el jurado estaba Álvaro Mutis. Cuando viví en Cartago me dediqué a escribir cuentos; me convertí en una especie de escritor extraño que mandaba cuentos a los concursos desde la provincia, sin padrino alguno y logré obtener dos premios nacionales consecutivos. Fue más tarde que incursioné en la novela.

Volvamos a la política. Han pasado cuarenta años de la utopía socialista. En estos cuarenta años ha pasado mucha agua debajo del puente. La Unión Soviética se acabó; el socialismo se vino abajo. Estamos viviendo una etapa llamada del capitalismo globalizado, del capitalismo salvaje. Tú, que tuviste un acercamiento al mundo desde la perspectiva analitica del marxismo, ¿crees que Marx sigue aún vigente?

Los problemas de los cuales se ocupó Marx siguen allí, y yo diría que se han agravado. Creo en la justicia social, en la solidaridad humana. Siempre me he alineado del lado de los que considero débiles o vulnerados y maltratados por la historia: de la causa femenina, de los indígenas, de las negritudes, de las minorías en general. El mundo, por fortuna, viene tomando un camino incluyente. La revolución femenina fue una de las revoluciones culturales más importantes de Occidente en el siglo XX. De imperceptible e invisible, el movimiento feminista reivindicativo se fue configurando, ahí está, es ahora menos fanático y está dando resultados a pesar de todas las dificultades. Creo que buena parte del análisis histórico de Marx sigue vigente, porque los problemas que analizó y trató de enfrentar siguen estando ahí. La revolución cultural femenina pudo darse y madurar porque no se propuso cambiar el modelo capitalista sino hacer parte de él.

¿Tú afirmas que, pese a la avalancha del capitalismo salvaje, el marxismo se integró al mundo como una práctica social?

No, se integró a los pensadores sociales y está implícito en la metodología de muchos analistas críticos.

¿Qué piensas de tu generación que se formó leyendo a Marx, Freud, Saussure, Lévi-Strauss y Dostoievski?

Los estudiantes de entonces y quienes posteriormente fuimos profesores universitarios, creíamos que el país nos iba a necesitar. Que, por 
lo tanto, debíamos estar formados intelectualmente para ser útiles a la sociedad. Nuestra generación tenía la esperanza de un futuro mejor. Yo no era utópico, digamos, y no transmitía la esperanza en una eventual utopía social. Era más bien realista, no idealizaba el mundo por venir. Pero el imaginario de la utopía social rondaba por aquellos tiempos en todas partes, incluso en las juventudes del mundo. Y la utopía implicaba luchar por una sociedad mejor. Tampoco creí mucho en la idea del progreso ascendente material y moral de la humanidad. Fui pesimista de la razón aunque optimista del corazón y de la vitalidad. La evidencia de dos guerras mundiales y el hecho de haber sido un hijo del destierro me hacían pensar que no podía ser tan optimista. Siempre pensé que la condición humana no daba para esperar mucho de ella, y creo que no me equivoqué.

Como diría Pascal, eras un realista a carta cabal.

Sí. Pero recuerda que Pascal propuso que el ser humano estaba gobernado por dos lógicas: la de la razón y la del corazón. Yo viví rodeado del mundo de la utopía, pero en el fondo era escéptico. Tal vez por esto estuve radicalmente del lado de Camus en su controversia con Sartre. Viví instalado en la sospecha del mundo. Quizás no era "políticamente correcto" decir esto abiertamente, sobre todo delante de los militantes misioneros entusiasmados salvadores de la humanidad, hoy moralmente descompuestos o en franca desbandada hacia las extremas derechas. De ahí que el componente analítico de Marx fue el que ciertamente me sedujo en aquel entonces y me permitió, no obstante mi escepticismo y pesimismo antropológicos, hacer parte de mi generación.

Tú hablas, y me surgen muchas preguntas.. ¿Qué pasó con esa generación utópica de los años 70?, ¿Cuál fue el futuro que corrió esa pequeña ilustración que en España, Colombia y América latina luchó por una sociedad mejor? ¿Esa generación fue arrollada por los acontecimientos? Parafraseando a Hemingway, ¿podemos decir que la generación del 70 fue una generación perdida?

Esta una gran pregunta que merece una reflexión seria y la respuesta no es fácil. Esa pequeña generación ilustrada, de la que tú hablas, tuvo algunas variables en América Latina. En el caso colombiano, puedo decir que el narcotráfico, la guerrilla de métodos criminales y el crimen 


\section{Fabio Martínez}

organizado incidieron negativamente en aquel proyecto por crear una sociedad mejor. De esta manera, la extrema izquierda criminalizada se burló de la utopía, convirtiéndose en caldo útil para la emergencia de una extrema derecha que, ante los métodos criminales de la guerrilla descompuesta, encontró importante legitimidad. De ahí sale el uribismo ideológico y político. Dicho en otros términos, la guerrilla y sus métodos criminales dieron origen a los paramilitares y al uribismo. Uribe no existiría sin la criminalidad de la guerrilla. Y en el uribismo fueron a recalar los intelectuales marxistas renegados y descompuestos.

Por supuesto, no toda la izquierda hizo parte de ese proyecto perverso que quería cambiar el país por medio de la lucha armada y la alianza con la mafia. Hubo muchos que nos quedamos en la academia, bajo el supuesto cierto de que la Universidad podía ser pensada como un espacio para la resistencia contra la hipermodernidad light y como morada del pensamiento racional. En la universidad nos dedicamos juntos con los jóvenes estudiantes a la comprensión de aquellas lógicas hipermodernas perversas que terminaron por borrarnos del mapa.

De los años setenta hasta hoy, los cambios han sido muy fuertes; ente otras cosas, porque el modelo socialista no aguantaba más. El socialismo real se convirtió en una vergüenza de la humanidad y a nombre de la humanidad también terminó haciendo cosas terribles, como ocurrió con el periodo oscuro del estalinismo. La mayoría de la izquierda apoyó a Sartre y unos pocos nos quedamos con el pensamiento de Camus. A Sartre lo admirábamos como una gran figura intelectual, pero asimismo veíamos en él una especial condescendencia y complicidad con el estalinismo. Camus jamás fue un renegado de la izquierda; siguió siendo un hombre de pensamiento de izquierda. Y, cuando digo de izquierda no quiere decir marxista. No necesariamente, sino de la izquierda que piensa el mundo de otro modo, instalado en la sospecha.

\section{¿Cuál era la diferencia fundamental entre Sartre y Camus?}

En su libro El hombre rebelde, Camus se plantea que el deber de todo revolucionario es seguirlo siendo incluso durante la revolución misma. Esto quiere decir que los seres humanos cuando hacen la revolución se adocenan y terminan haciendo cosas aterradoras para mantener los privilegios logrados. Para Camus, hay que seguir siendo re- 
volucionario dentro de la revolución; hacer rupturas, proponer nuevas transformaciones para que el individuo no se vuelva de piedra y se entregue al aparato burocrático. Sartre pensaba que había que consolidar el socialismo a pesar de todo y fue conciliador con algunas atrocidades de Stalin, porque para él lo fundamental era salvar el socialismo frente al capitalismo. Ahora vemos que Camus fue visionario. Y, todo, por su preocupación respecto de la ética de los medios, por encima de la ética de los fines. Lo que hizo de la guerrilla colombiana una pandilla criminal fue precisamente la validación de todos los medios de lucha por fuera de todo límite ético.

O sea que el punto de vista de Camus fue mucho más radical que el de Sartre.

Pienso que sí, en cuanto se supo situar de manera innegociable en la ética de los medios. Camus fue más radical que Sartre porque fue independiente. Jamás se inclinó frente al estalinismo y sus métodos, como garantía del futuro del socialismo. Pero, además de esto, Camus fue un gran escritor. Sartre fue un filósofo que puso su literatura al servicio de sus tesis filosóficas. En cambio, Camus diferenció el mundo de sus ideas del mundo específico de la literatura. La literatura, para Camus, no podía ser objeto de servilismos ideológicos, como pienso que sí lo fue para Sartre.

Para volver a la pregunta del comienzo, pienso que hubo tres caminos por donde se escurrió la generación del 70: uno, el camino criminal; otro, el camino del cinismo; y el tercero, el camino de la resistencia y la comprensión crítica de los procesos; entre ellos el declive crepuscular de los grandes relatos propios de la mítica moderna, tales como el mito del progreso material y moral de la humanidad, la falsa idea del sujeto humano centrado en la razón y, en tercer lugar, la idea de que la Historia era occidental y blanca, y debía ser pensada como el relato que narraba, precisamente, la manera como la Razón dirigía a la humanidad hacia una salida futura de progreso material y moral. Y toda esta mítica se derrumbó y es, de este derrumbe, que brota la subjetividad hipermoderna.

A lo largo de estas últimas décadas hemos visto cómo la utopía fue palideciendo y quienes creíamos en ella de pronto nos quedamos colgados de la brocha y la escalera en el suelo. Debido a los extremos de 
izquierda y de derecha, nos quedamos por fuera de la historia y ésta continuó su rumbo inusitado hacia los excesos de lo moderno. A esto debo agregar lo que ha advertido George Steiner en sus ensayos: la caída de la cultura letrada y el domino absoluto del mundo mediático. Esto nos dejó inermes.

Es cierto que el proyecto utópico en el país se vio sofocado y malogrado, tanto por la extrema derecha como por la extrema izquierda. La criminalidad de la guerrilla y su descarrilamiento respecto de los principios fundamentales legitimó social y políticamente a una extrema derecha, que creó en el país el fenómeno del paramilitarismo. Eso fue lo que sucedió en Colombia. Pero ¿qué sucedió en el sur del continente? En la década del 70 miles de militantes de izquierda, de escritores e intelectuales progresistas fueron encarcelados, muertos y desaparecidos por las dictaduras militares.

Lo estás diciendo. Las dictaduras militares en Brasil, Uruguay, Chile y Argentina fueron las encargadas de sofocar a sangre y fuego la generación de la utopía. El símbolo de la lucha contra las dictaduras hoy está encarnado en el poeta Juan Gelman y en las Madres de Mayo. Es terrible decirlo, pero en Argentina lo que quedó de la utopía, por idealista que hubiese sido, son las "huérfanas" Madres de Mayo. Sus hijos fueron lanzados al mar desde los aviones de Galtieri y de Videla.

\section{La Universidad como campo de resistencia civil}

Volvamos a Colombia. ¿En qué año te vinculas a la Universidad del Valle?

En 1972. Yo estuve en la Universidad Santiago de Cali por un corto tiempo. Luego fui nombrado en la Universidad del Valle, en la Facultad de Ciencias Económicas y Sociales, ubicada en la sede del barrio San Fernando. Entro junto a una lúcida generación de catedráticos como Bernardo García, Alberto Corchuelo, Jorge Villa Cantillo, Henry Arboleda y Álvaro Camacho Guizado, entre otros. Profesores inolvidables. Corría el año de 1972. Yo era muy joven. Entre febrero y mayo de aquel año se generó un importante movimiento estudiantil y a raíz de estos acontecimientos la Universidad fue cerrada. Los nuevos profesores y 
un grupo de dirigentes estudiantiles fuimos expulsados, destituidos por el gobernador de entonces, el doctor Marino Rengifo Salcedo, presidente del Consejo Superior. Los profesores interpusimos una demanda ante la Jurisdicción Contenciosa Administrativa y la ganamos. Esto ocurrió en el año de 1978. Durante la rectoría de Álvaro Escobar Navia nos reintegraron a la Universidad.

¿O sea que pasaste seis años por fuera de Univalle?

Sí; luego, como te dije, ganamos una demanda y fuimos reintegrados al alma mater.

\section{¿Desde cuándo asumes el oficio de escritor?}

Desde que escribí los primeros poemas. Muy joven viajé a San Francisco y allí, quizás influenciado por los movimientos estudiantiles que se vivían en California, escribí mi primer poema, titulado: $L S D$, San Francisco media noche. El poema fue publicado en "Lecturas Dominicales" del diario El Tiempo, cuyo director en ese entonces era el periodista y poeta Álvaro Burgos.

¿En qué año fue escrito este poema?

En 1964. Yo tenía veintiún años. El Departamento de Estado Norteamericano invitó a un grupo de estudiantes líderes a conocer los Estados Unidos. En este grupo estaban Humberto De la Calle, el padre de Armando Benedetti y Julio Valdivieso Torres. Entre las ciudades a visitar, además de New York y Washington, por supuesto, estaba San Francisco y de manera especial la Universidad de Berkeley. Fue una experiencia tan inquietante y transformadora como la vivida, guardadas las proporciones, por Lorca en New York. Quien lee este poema suyo, de inmediato entiende que en esta ciudad Lorca fue otro. A raíz de este viaje, me interesé por la generación beat y leí con juicio a Allen Ginberg. Desde aquel mi primer poema, asumí la escritura como parte esencial de mi vida. Escribía o moría. Era algo así como un vaciamiento visceral, hondo y comprometido. Luego vinieron los cuentos, que escribí cuando al terminar mis estudios universitarios en Bogotá, debí radicarme en Cartago como juez. Fue aquella una época productiva. Allí leí $E l$ gran serton: Veredas, del escritor brasileño Joao Guimarães Rosa. Con Guimarães hice consciente, deslumbrado, la potencia del lenguaje. En 
Cartago nació mi primer libro de cuentos: Las alabanzas y los acechos.

Si un escritor encuentra un pequeño auditorio ávido de leer ensayos, novelas, cuentos; o por lo menos, encuentra un lector, el escritor está salvado.

Sí, porque el primero y más exigente lector de su propia obra es uno mismo. Sin embargo, cuando voy a Medellín, Bogotá, Bucaramanga, Pereira, Calarcá o a cualquier otra ciudad del país, encuentro muchachos que han leído mis libros. Algunos profesores hacen fotocopias de mis artículos y ensayos como parte del material para seminarios y cursos. Esto reconforta, en medio del escepticismo. Estos jóvenes, además, comparten la idea de que el escritor debe ser, ante todo, un hombre de pensamiento. Siento placer genuino al leer ensayos en los auditorios de las universidades donde soy invitado, porque éstas siguen siendo el nicho ideal para preservar el pensamiento. La Universidad, sobre todo la pública, es de los pocos espacios de resistencia civil que nos queda para preservar el uso público de la Razón en términos kantianos, difundir la cultura letrada y el Pensamiento Crítico.

\section{La modernidad, el sujeto y las redes sociales}

En tus libros, La sombrilla planetaria y La tierra que atardece, tú haces una interesante reflexión sobre la modernidad. ¿Los presupuestos básicos de la modernidad siguen vigentes?

Sí, estos dos libros de ensayos están dedicados a pensar la modernidad. Soy hijo y defensor de la modernidad, a sabiendas de sus excesos. Sus principios básicos están a la orden del día. No hay un sólo "postmoderno" que nos defienda. Por ejemplo, el principio de individuación hoy está exacerbado. Lo que hoy existe no es una postmodernidad sino una hipermodernidad. Ningún postmoderno niega la libertad, ni la igualdad de derechos ni el principio de la autonomía de la voluntad. Mucho menos el principio de la dignidad humana y el respeto a ella. Todos hablan en contra de la Razón, pero para ello utilizan todos los más refinados recursos argumentativos que la Razón ofrece. No es que no haya pasado nada a la modernidad. Lo que ha sucedido es una crisis de su mitología y de sus imaginarios, pero los valores modernos están ahí, vigentes y en uso. 
¿El concepto de la libertad del individuo sigue vigente?

¿Te refieres a la autonomía del sujeto?

Sí, por supuesto.

El concepto de la libertad del individuo no solamente sigue vigente sino que se ha potenciado y exacerbado. Estamos en un mundo hiperlibertario. Un mundo en el que la idea del límite es molesta. Hoy los límites son mínimos. Ellos impiden el goce de la vida y el mundo de hoy es hedonista y narciso. Además, como dice Redeker, el Yo del sujeto hipermoderno se ha ido al cuerpo.

Me imagino que se ha potenciado a través de las redes sociales, de las nuevas tecnologías virtuales. En Facebook hay un afán narcisista por cambiar permanentemente el perfil de sus usuarios.

Sí, en Facebook y twitter los sujetos están gritando al mundo lo que son a cada segundo que pasa: Los sujetos virtuales aúllan: "Yo existo"; y lo hacen con auto-foto (selfie), lifting y todo.

Así, muchas veces, la información en Facebook sea esquizofrénica y mentirosa.

Lo que uno nota en el Facebook es el desespero del yo contemporáneo, lanzado no exactamente a la soledad, que es deliciosa cuando es elegida, sino al vacío de sí mismo y de su vida. Los desesperados aullidos humanos que se escuchan en Facebook, aunque quienes los lanzan no lo entiendan así, no provienen de la soledad sino del absoluto vacío de las vidas de la mayoría de sus autores. Y no por "culpa" de quienes aúllan, sino porque nuestro tiempo ha configurado sujetos unarios, autoreferidos y no sujetos binarios, alter-referidos y alter-constituidos, según Dany-Robert Dufour.

Parafraseando a Freud, el Facebook es como una especie de striptis del ideal del yo. Ahora todo lo íntimo y privado se ha convertido en público.

Claro, aunque con esta precisión: según Redeker, en Egobody, el yo del sujeto hipermoderno se ha ido a vivir a la experiencia del cuerpo y su belleza física. El yo se confunde ahora con el cuerpo. La distancia entre el yo y el cuerpo, que es su morada, se ha esfumado. Y la intimidad ahora se ha vuelto espectáculo, según la antropóloga argentina Paula Sibilia. 
Fabio Martínez

La intimidad, que antes pertenecía al orden personal, se ha convertido en pública.

Exacto. Pero, más que en pública, en espectáculo mediático para el goce de todos. Y es muy rentable para quienes tienen montado el negocio de la exhibición de lo íntimo.

Ya no existen fronteras.

Porque antes el refugio de la intimidad era el secreto. Este secreto era invulnerable y debía ser respetado. Ahora, el refugio de lo íntimo no es el secreto en cuanto la intimidad se hace pública. El refugio actual de la intimidad consiste en no ser juzgado. A los jóvenes de ambos géneros se les pone el pelo de punta cuando son juzgados. No quieren ser juzgados moralmente. Tú te expones públicamente y nadie debe juzgarte.

Te tienen que aceptar como eres, asi tu información personal sea alterada. Te tienen que mirar como apareces, asi tu apariencia no tenga nada que ver con tu ser. Mejor dicho, te deben aceptar como te representas.

Allí, en lo que dices, hay un cambio muy significativo de la modernidad. Pero debo agregar que, en mi opinión, dichos cambios en la subjetividad contemporánea se están produciendo a través del marketing de la imagen humana, es decir de la comercialización del yo y de su cuerpo convertido en objeto de exposición estética en busca de la belleza perfecta. Pienso que, ahora, la imagen pública del cuerpo expuesto mediáticamente, que expresa al yo en su belleza cosmética y de quirófano, ha transformado de manera dramática el mundo psíquico que se produjo, según Lacan, a partir de la invención técnica del espejo. El espejo de hoy no es el de Lacan, sino el de las auto-fotos que van a volar por el mundo en el Facebook y el del marketing que impone la belleza del cuerpo como ideal del yo. El ideal del yo del sujeto hipermoderno no es un ideal de valores provenientes de la filosofía, de la ética o de la política, sino el ideal que impone el marketing del yo y de su belleza cosmética. ¿Tú no crees que al exponerse la individualidad, el ser humano está, digámoslo así, arriesgando su propia intimidad? ¿Está poniendo en riesgo su naturaleza de ser ante la apariencia del ser? 
Lo que está claro es que todos estos cambios hipermodernos están produciendo un nuevo tipo de sujeto humano. Esto lo dice Dany-Robert Dufour en su libro El arte de reducir cabezas. Es un libro magistral en el que sostiene que en el mundo actual ha desaparecido el sujeto neurótico freudiano y el sujeto crítico kantiano. Y que, por tanto, agrego yo, estamos ante un proceso de fabricación mediática del sujeto. Hay montada una fábrica de subjetividad. Los sujetos humanos siempre son productos socialmente, esto es inevitable. Y configurados según los parámetros culturales de época, según Charles Taylor. Pero, en la hipermodernidad neoliberal, la subjetividad es producida ahora por la máquina social de los medios masivos de comunicación y el marketing del yo. Los neuróticos éramos nosotros. Nuestra generación consideró que el mundo estaba mal hecho. Ahora los jóvenes consideran que esto está supremamente bien hecho. Que la vida es para gozarla y quien no se la goza está de malas. Los jóvenes, en general, no tienen una actitud crítica frente a lo que viven, a duras penas se "indignan" pero de ahí no pasan.

En la postmodernidad el sujeto crítico también fracasó. La figura del intelectual y del escritor de pensamiento, que venía de la Ilustración francesa, se agotó.

El intelectual era un ser desadaptado frente a la sociedad que criticaba.

Por esto es que en los grandes medios ya no se tiene en cuenta la voz del intelectual, del escritor. Las editoriales prefieren publicar libros de religión, cocina y autoayuda, y desechar a los buenos escritores. Fernando, ¿hacia dónde vamos? ¿No será que toda esa basura informativa nos va a cubrir del todo hasta devorarnos?

No, no lo veo así.

¿¿No?! Yo sigo siendo un nihilista. Nietzscheano o schopenhariano, para más señas. ¿Tú qué crees? Pensemos en el futuro incierto que ya comenzó. Juguemos un poco al adivino.

Uno mira el futuro a partir de las tendencias. Ellas señalan para dónde vamos. Creo que vamos hacia el vacío del yo. En estos días estaba releyendo a Vattimo y el nihilismo, según él. Y resulta que Heidegger, 
pero sobre todo Nietzsche, auguraron que el sujeto humano quedaba convertido, ante todo, en valor de cambio.

\section{¿En mercancía?}

Sí, claro, en una mercancía intercambiable. Y para esta sociedad, los seres humanos ya no valen por sus principios, por sus valores humanos, por lo que sepan en términos de conocimiento, por su cultura, sino por lo funcionales que sean al sistema. Los seres humanos tienen que estudiar para ser funcionales, y las mujeres y ahora los hombres tienen que ir al quirófano para participar con éxito en el mercado de la carne y de la imagen exitosa. De lo contrario salen del circuito, salen del mercado. Yo creo que esa es la tendencia del mundo actual. Pero, hay que decirlo, la capacidad humana de resistir y criticar estas tendencias no ha muerto. Miles de muchachos las enfrentan con valor e inteligencia. Y construyen vidas al margen de estas tendencias y se burlan de ellas. Tienen hijos a quienes les trasladan su mirada crítica y demoledora. Pero, esto no es que me llene de esperanza, sino que me hace mirar el mundo de hoy a partir de la diversidad y la complejidad. Llevo 40 años como profesor universitario, y tengo la certeza de que, al margen del marketing del yo e independientemente del declive de la cultura letrada y su sustitución por la cultura light y banal, existen preciosos núcleos humanos invisibilizados por el marketing aplastante, que están ahí, en la resistencia y en la construcción, para sí, de un mundo alternativo.

Por otra parte, todo esto tiene que ver, también, con la variable de la edad y el género. Los jóvenes están allí, en aquel mundo mediático de la oferta y demanda hasta los treinta años. Pero después, cuando la vida los obliga a hacer un alto, comienzan a pensar de otro modo un poco más trascendental. La sensación de vacío de la que habla Lipovetsky y que algunos sienten, comienza aproximadamente a los treinta años para las mujeres y a los cuarenta para los hombres. Es la edad en la que algunos suelen cuadrar caja.

La reflexión comienza cuando uno comienza a hacerse adulto. “¿Cómo fueron mis años de juventud mientras estuve conectado a una red chateándome con mis amigos?" Es la pegunta que los seres humanos se comienzan a hacer en la edad madura. 
Pero quizás ya sea tarde, porque los ideales del yo no se construyeron a partir de preocupaciones políticas, filosóficas, de conocimiento, ni éticas, sino sólo a partir de patrones de éxito provenientes del marketing, insisto.

Sigamos jugando a la futurología. ¿Cuál será el destino de esas generaciones formadas en las redes sociales?

Creo que van a regresar de cabeza al misticismo. Porque si algo produce la "era del vacío", del que habla Lipovetsky, es el retorno neo-místico. Los seres humanos que se sienten vacíos y que sienten que no fueron exitosos no regresan a la Razón y sus fuertes exigencias, sino a sistemas de pensamiento pseudoancestrales. Retornan al animismo resignificado, a las religiones en sus formas primarias y al espiritismo. La energía positiva de hoy no es más que una nueva versión de lo que Freud denomina como la omnipotencia de las ideas. Esto tiene íntima relación con el pensamiento mágico. En síntesis, la sensación de vacío a la que pueden llegar luego del "cuadre de caja" ciertos hombres y mujeres, nunca termina por lanzarlos a los rigores de la Razón sino a formas primarias de consuelo y neo-ancestrales otorgadores de sentido.

Quizás por esto es que hoy pululan en el mundo toda suerte de religiones y misticismos. Hoy en día un pastor crea una secta en el garaje de su casa.

Esto coincide con la desaparición del sujeto crítico.

Por lo tanto, con la desaparición del escritor, del intelectual.

Esto depende del tipo de escritor y de intelectual de los que estemos hablando. Paulo Coelho es un verdadero prodigio del renacer de lo primitivo resignificado en lo contemporáneo y llena el vacío de nuestro tiempo. Coelho dice precisamente lo que la demanda ansiosa espera. Es el autor típico que quiere calmar el desasosiego de nuestro tiempo. Pero, si estamos hablando del escritor complejo y crítico, categoría dentro de la cual me ubico, es evidente que estamos por fuera del mercado. Pero, aún así, contamos con lectores de élite intelectual que nos valoran y aprecian. Por otro lado, este mundo de hoy necesita ser interpretado. Y, quienes están en condiciones de interpretarlo no son los consoladores de oficio convertidos, por esto mismo, en éxito editorial, sino quienes en uso de la Razón y mediante el concurso de las ciencias humanas y 
sociales, descifran los tiempos históricos. La demanda de este tipo de escritores e intelectuales está en las universidades y en ciertas capas intelectuales que están ahí y que resisten con dignidad.

\section{La neurociencia y el trasplante del yo}

El tema de las tecnologías virtuales está muy articulado al desarrollo de las ciencias. Hoy en día ya se hacen trasplantes de órganos humanos, se reemplazan partes del cuerpo que el cirujano puede programar y monitorear a través de un computador. Lo único que nos hace falta es hacer trasplantes de la conciencia humana; o lo que se ha llamado, mutaciones del yo. Una perspectiva que jamás imaginaron Nietzsche y Foucault.

El trasplante del Yo ya se está haciendo sin necesidad de hacer cirugías. Hoy en día el ser humano vive una mutación del Yo, porque el Yo es histórico. Desde el punto de vista del psicoanálisis hay una estructura psíquica que comprende el Yo, el Ello y el Súper yo, como suele decirse. La personalidad de un individuo es histórica. El Ello, digamos, es una dimensión básica que está allí en los seres humanos como naturaleza suspendida, según Agamben, pero los inhibidores normativos del Ello son históricos. Lo mismo sucede con los ideales del Yo. Tú no puedes tener en el periodo esclavista los ideales del yo moderno. Es imposible. Ahora bien, el Súper yo es riguroso y fuertemente normativo en el mundo moderno. En el mundo hipermoderno el Súper yo es supremamente flexible. En el mundo actual tú no encuentras que el Súper yo sea un tirano moralista. Hoy la sexualidad es un derecho, no un tabú. Y esto abrió a la humanidad a otra mirada sobre el cuerpo y el mundo.

Tú decías que el Yo es histórico, que de alguna manera ha mutado.

El Yo ha sido modificado por la cultura. Cuando tienes una cultura muy permisiva de las pulsiones, por un lado, y por el otro un debilitamiento de la normatividad interiorizada propia del Súper yo, entonces el Yo está menos afligido. El Yo está siempre en cuña fuerte entre las normas y el deseo. Pero la fuerza de esta tensión no ha sido siempre la misma. Ahora, en la sociedad y en las redes sociales, el deseo se pasea por los jardines en flor. El deseo flota libre por todas partes, sin mayores 
límites. Obviamente los límites existen, pero no hay equivalencia con otras épocas. Este Yo contemporáneo vive en un espacio de permisibilidad y de libertad mucho mayor. Pero el yo, a su vez, es el lugar desde donde se habla. Desde el punto de vista psíquico el Yo es la conciencia deliberante y auto referida que le habla a sí mismo. Es decir, el Yo es un espacio psíquico de auto referencia constante. En su libro Las fuentes del Yo, Charles Taylor parte del supuesto de que el Yo tiene unas fuentes y que esas fuentes vienen de lo que él llama los "marcos de referencia ineludibles". Y estos marcos de referencia ineludibles no son otros que los conformadores culturales del Yo. El Yo no se conforma desde adentro de sí mismo, autárquicamente, sino desde la cultura y desde estos marcos de referencia imposibles de eludir.

Cuando tú naces en una sociedad moderna no puedes eludir creer en la libertad, no puedes eludir considerar que los seres humanos son iguales, que son dignos de respeto, que tienen derecho a una vida digna, etc. Esto no sucedía en la Edad media ni en el período esclavista. El Yo en aquellas épocas no era así.

Ahora bien, ¿cuál es el Yo de hoy? El Yo moderno estaba centrado en la idea de futuro porque en el futuro estaba el progreso, el porvenir, la salida en términos de progreso moral y material de la humanidad. El Yo del hipermoderno, propio de los jóvenes de hoy, está centrado en el presente. Hay que vivir y gozarse el presente. Por esto, el Yo de los jóvenes de hoy es hedonista, no sacrificial. Por el contrario, el Yo moderno clásico de los siglos XVIII y XIX se construyó culturalmente alrededor de una ética sacrificial. Se sacrificaba el goce del presente en favor de metas de valor moral, político o intelectual. Nuestra generación fue dominada por una ética sacrificial, porque creíamos que debíamos postergar el disfrute del presente por privilegiar metas futuras en favor de una sociedad mejor y todas estas quimeras. Te voy a hacer un listado del espíritu del sujeto contemporáneo. No se trata de insultos sino características fundamentales, así: el Yo del sujeto hipermoderno es hedonista, apolítico, narciso, autoreferido y unario, desideologizado, presentista, banal, no sacrificial y líquido, según Bauman. Es decir; en la época actual del hipermodernismo, los vínculos y las relaciones humanas tienden a ser líquidas y circunstanciales. 
De un mundo sólido y aparentemente seguro, pasamos al mundo líquido, efimero y circunstancial.

A diferencia de nuestra generación, los jóvenes de hoy no entablan vínculos duraderos. Las relaciones afectivas son de paso, los matrimonios se disuelven a los tres años. Los hijos, si hay que dejarlos tirados a su suerte, se abandonan porque hay que irse a gozar mi vida. Los vínculos de los electores con los partidos y sus líderes no están basados en compromisos fuertes de ideas y de valores, sino en razones circunstanciales de pura coyuntura y hasta de gusto.

El pensamiento líquido, fugaz y liviano se sobrepuso al pensamiento sólido y comprometido.

Así es. Los jóvenes hoy son refractarios a todo tipo de ideologías que impliquen compromiso de larga duración; están por esta misma razón despolitizados.

Esto se está viviendo hoy con la televisión. La juventud se pliega a esa avalancha masiva generada por la televisión y el marketing.

Sí, esto es claro. Están viviendo el presente, lo están gozando. Lipovetsky también dice que el joven de hoy no tiene una ética sacrificial, porque no está dispuesto a sacrificarse por nada, ni por nadie. Los jóvenes dicen, incluso en las empresas donde trabajan: yo vengo aquí por lo mío, yo vine a este mundo por lo mío.

La hipermodernidad está magnificada por la imagen, que es la nueva tirana del mundo. Desde los antiguos la imagen siempre ha cumplido la función de sobredimensionar el objeto.

Este es el problema, si es que así puede llamársele. Los marcos referenciales contemporáneos de la construcción del Yo, que durante los siglos XVIII, XIX y mitad del XX fueron construidos alrededor de valores humanistas solidarios y generosos, por decirlo de algún modo, al parecer pasan ahora a ser propuestos por el marketing y los valores que el consumo impone. Hoy existe la fábrica que produce la conciencia, según Salmon. Y esa fábrica es de propiedad privada y es intencional.

Pero esto traerá sus consecuencias a nivel de la construcción del sujeto.

No soy apocalíptico en el sentido de decir que todo está perdido. 
Cuando se estaba disolviendo la Edad media los aristócratas decían: "Este mundo se acabó", y el que se estaba acabando era el mundo de ellos. Lo único que me impresiona y ante lo cual me levanto críticamente es que, tal como acabo de decirte, la fábrica de producción de la conciencia es de propiedad privada y es intencional. Esto produce sujetos que se creen originales y únicos, pero que en realidad son absolutamente estándar. Piensan lo mismo, tienen los mismos ideales de éxito impuestos, creen que usan ropa exclusiva y hasta caminan idéntico. Son clones hijos del marketing y de los medios masivos intencionados.

\section{¿Tú tienes una mirada optimista frente al presente?}

$\mathrm{Ni}$ optimista ni pesimista, sino realista. Cuando irrumpió la individualidad moderna y se fueron configurando los ideales de igualdad y libertad humanas, los aristócratas aullaban que este mundo se iba a acabar. Y, ciertamente se acabó, pero no el mundo sino el mundo de ellos montado en exclusiones de sangre y linaje. Por principio, no pienso que todo tiempo pasado fue mejor. Cuando uno piensa de este modo, es seguro que ya está anciano y conservador. Conozco la letra de un tango, de Homero Manzi, que dice más o menos, así: "Quien crea que todo tiempo pasado fue mejor, ni fue obrero, ni fue mujer, ni fue trabajador".

Ahora bien, este tipo de sujeto contemporáneo hipermoderno típico y estándar, hay que entenderlo, propongo, como una construcción mediática, como un producto fabricado intencionalmente, en masa, a través del proceso industrial de producción de la subjetividad y la conciencia. La Iglesia en su momento produjo conciencia y subjetividad en masa y estándar pero lo hizo con fines morales, por horrible que esto pudiese parecer ahora; nuestra escuela moderna, produce subjetividad y conciencia modernas en masa y estándar, pero introduce al mismo tiempo el principio de la libertad de pensamiento, de la autonomía del sujeto moral individualmente responsable y prohíja valores de igualdad humana, libertad, dignidad y respeto.

En fin, la subjetividad siempre se produjo desde afuera del sujeto mismo. Pero, hoy, lo que no acepto es que la producción de subjetividad, más allá de la escuela como aparato social del Estado en sus funciones, haya sido atrapada de un zarpazo invisible por la fábrica privada de producción de subjetividad y de conciencia intencional, a través de 
los medios masivos y el marketing del yo. Esto me indigna. Es un deber denunciarlo y atacarlo. Pero insisto, en que no todo está perdido, porque conozco innumerables jóvenes y adultos por fuera de las lógicas de esta fábrica tenebrosa, de manera consciente y deliberada.

Lo que has dicho es lo problemático. Detrás de los noticieros, los realities y las "noticias en desarrollo", existe toda una maquinaria del mercado. La construcción del sujeto está determinada por las leyes del mercado.

Que los sujetos se transformen y formateen históricamente según metas de valor, vaya y venga. Esto es lo normal. Pero que a ti te impongan desde la cultura de masas y el marketing privados y con fines utilitarios sólo para ellos, un sujeto a la manera de un modelo intencionalmente dirigido, esto es reprochable. Absolutamente inadmisible. La cultura popular es muy distinta de la cultura de masas. La cultura de masas que produce y agencia la televisión privada es ella misma una fábrica industrial de subjetividades. Y el marketing instala ideales del Yo y de éxito absolutamente dirigidos y a su servicio. A ti y a todo el mundo te ponen a mamar de esa cultura.

Ahí es donde pienso que falta una juventud más crítica y contestaria frente a esto. El ser humano no puede ser el idiota útil del marketing, el fashion $y$ el selfies.

Esa juventud crítica se hace en las universidades y colegios con "buenos" profesores. En donde "buenos" quiere decir críticos y analíticos.

En lo que a mí concierne como asunto de mi responsabilidad ética, lo veo entre mis estudiantes de administración de empresas... Parecería insólito. Sin ser ellos estudiantes de Humanidades, Arte o Literatura, reciben con inmenso entusiasmo las lecturas de ciencias humanas que les propongo desde una perspectiva crítica. La educación crítica y analítica es un instrumento de inmenso valor en la creación de subjetividad conciencia. Y los estudiantes lo agradecen porque sienten que sus vidas se transforman. Uno a veces siente que arar en el mar es inútil, pero hay que hacerlo. No hacerlo es inmoral. No vinimos a este mundo a dejar que la mierda nos cubra y a comer mierda felices, pensando que todo 
así está bien. Por esto sigo pensando que las universidades deben convertirse, urgentemente, en espacios de resistencia cultural. Es allí donde puede producirse otro tipo de subjetividad, crítica, pensante y analítica.

A través del marketing los medios de comunicación impulsan las telenovelas donde se hace una apología a los capos de la mafia. Los guionistas de esas series, que están cooptados por el mercado, viven "comiendo del muerto". ¿Por qué en Colombia se acabaron las series adaptadas de las grandes novelas de la literatura? Aqui hay una manipulación del sujeto que se exporta al mundo.

Esto tiene que ver con los ratings. Es que la televisión aquí se rige por un principio: debe ser rentable. Las series sobre mafia, venden. Y venden muchísimo. El país se debate entre la mediocridad y el mal gusto y la apología del submundo inmoral y criminal. No me estoy refiriendo a lo popular ético y hermoso, sino al submundo criminal e inmoral que existe incluso en el estrato seis. El submundo del que hablo, el nuestro, está lejos de parecerse al que describió Dostoievski en sus novelas.

A los canales privados ya no les interesa la literatura como arte sino como mercancía. Yo recuerdo que hasta hace algunos años la televisión colombiana llevó a la pantalla novelas muy buenas como La casa de las dos palmas de Manuel Mejía Vallejo. Después, una serie llamada Café, de muy buena factura actoral. Pero, al parecer, es mucho más rentable el mal gusto y el mundo criminal como tema. Y el punto aquí es el negocio y la rentabilidad. Esto lo explica todo. Además, esta lógica también se apoderó de la literatura. Las casas editoriales prefieren por buen negocio este tipo de temas. El marketing literario o televisivo no consiste en que los productos se vendan. Vender productos culturales es normal y aceptable. No existe el menor reparo en esto de vender. El marketing literario y televisivo parte de un principio fundamental del marketing, a saber: el cliente siempre tiene la razón y hay que ofrecerle lo que le gusta y demanda. Es decir que la oferta se pliega por completo a la demanda. De esta manera, si el cliente desea calcetines morados, pues hay que producirlos. Llevado este principio de tiranía del cliente a la literatura y a la televisión, el resultado es catastrófico, pues lo que se escribe o se muestra en la pantalla es lo que el cliente quiere que le 
ofrezcan. Entonces tenemos escritores y productores de series televisivas arrodillados ante los bajos gustos de la clientela, dedicados a exaltar los fondos criminales y sus lenguajes casi onomatopéyicos primarios, felices porque se convierten en "artistas" exitosos en las ventas. Y la estética se va al piso.

Las famosas noticias en desarrollo, que pueden durar dos y tres horas seguidas, representan la nueva tiranía de los medios sobre el televidente.

Sí, durante veinte días vimos fútbol. Nos gusta el fútbol, amamos el fútbol, pero las noticias del país y del mundo se acabaron en esos veinte días. No sé si esto ocurre en Colombia nada más, donde los locutores que más gritan y se inventan partidos que no están sucediendo en la cancha son los mejores y los más solicitados por la clientela.

La televisión es el nuevo imperio mediático que construye, a punta de pauta publicitaria, un sujeto dócil, pasivo y complaciente.

Así es, mi querido Fabio. Sobre todo, ese tipo de sujeto típico hipermoderno cuyos ideales del yo y de éxito en el mundo son impuestos por los medios masivos en asocio con el marketing consumista. En esta alianza hay en desarrollo una fábrica de subjetividad al servicio de evidentes intereses privados. Una fábrica imperceptible e invisible que es nuestro deber denunciar. Esto ha quedado planteado ya antes. Llegará el día en que el yo del sujeto se confunda tanto con una CocaCola y con su cuerpo que tendrá un mejor sabor que la Coca-Cola. Se trata de un chiste y de una exageración, claro; pero quiere indicar un camino de reflexión.

Entrevista tomada de:

http://ntcdocumentos.blogspot.com/2015_01_03_archive.html 